\title{
Perception, Concern and Acceptability of Neonatal Male Circumcision among Postpartum Mothers in Thailand
}

Boonlure Pruenglampoo', Kriengkrai Srithanaviboonchai ${ }^{1,2}$, Richard M. Grimes ${ }^{3},{ }^{4 *}$, Deanna E. Grimes ${ }^{3,5}$, Jiraporn Suwanteerangkul², Jiraporn Khorana ${ }^{2}$, Knittha Thaikla ${ }^{1}$, Vipa Danthamrongkul ${ }^{6}$, Suchada Paileeklee ${ }^{7}$ and Uraiwan Pattanasutnyavong ${ }^{8}$

${ }^{1}$ Research Institute for Health Sciences, Chiang Mai University, Chiang Mai, Thailand

${ }^{2}$ Faculty of Medicine, Chiang Mai University, Chiang Mai, Thailand

${ }^{3}$ Baylor-UT Houston Center for AIDS Research, Texas, USA

${ }^{4}$ Division of General Internal Medicine, University of Texas Health Science Center at Houston, Texas, USA

${ }^{5}$ School of Nursing, University of Texas Health Science Center at Houston, Texas, USA

${ }^{6}$ College of Public Health Sciences, Chulalongkorn University, Bangkok, Thailand

${ }^{7}$ Faculty of Medicine, Khon Kaen University, Khon Kaen, Thailand

${ }^{8}$ Faculty of Medicine, Prince of Songkla University, Songkla, Thailand

\begin{abstract}
Introduction: Three randomized controlled trials involving over 11,000 men have demonstrated that male circumcision reduces female to male transmission of HIV. It is recommended by the World Health Organization as part of a HIV prevention program. Adult male circumcision is associated with significant complications while neonatal male circumcision (NMC) has few risks and may be a preferred prevention strategy. Internationally, NMC is seldom performed except as a religious ritual. So, introducing NMC in Thailand needs to determine its acceptability among mothers. Therefore a study was conducted among postpartum Thai mothers to determine their perceptions of, concerns about and acceptability of NMC.
\end{abstract}

Methods: A survey was conducted of 593 postpartum mothers from 16 hospitals in 4 provinces in Thailand. Data were analyzed using descriptive statistics, univariate analysis and binary logistic regression.

Results: $70 \%$ of the participants reported that they knew or have heard about MC. Safety and pain were the major concerns of the mothers towards NMC. One-third would chose to have their infants circumcised after receiving the information about NMC, an additional third were undecided and $34.5 \%$ would not allow their sons to undergo NMC. Mothers $(44.0 \%)$ were the most influential person when it comes to the decision on NMC followed by fathers $(37.9$ $\%)$. In a multiple regression, having 9 years or greater of formal education (OR 1.64; $95 \% \mathrm{Cl} 1.01-2.66)$, having a circumcised husband (OR 2.88; $95 \% \mathrm{Cl} 1.11-7.50)$, and knowing of at least one circumcised child $(\mathrm{OR} 1.97 ; 95 \% \mathrm{Cl}$ 1.22-3.18) were independent predictors of acceptability to NMC among postpartum mothers.

Conclusions: The results suggest that NMC may be culturally neutral with evidence that even modest educational efforts can impact mothers' decisions in favor of NMC. However, this study and a previous study suggest that both parents and health professionals need to be educated about the benefits of NMC.

Keywords: Neonatal male circumcision; HIV /AIDS; Prevention; Thailand; Perception; Acceptability; Postpartum mothers

\section{Introduction}

The famous management writer, Peter Drucker is alleged to have said "Culture eats strategy for breakfast," suggesting that changes in an organization must overcome deep seated resistance to changes by employees. Merely having a strategy is insufficient. While this adage was meant to apply to organizational cultures, it can be applied to community cultures as well. Bearing this in mind, advocates of introducing neonatal male circumcision (NMC) in Thailand have begun a series of studies to examine the cultural and practical issues that may interfere with its adoption [1,2]. As a strategic choice, there is much to recommend male circumcision (MC) as an effective biomedical HIV prevention strategy in heterosexual males. A metaanalysis of studies on circumcision showed that the relative risk of female to male: transmission of HIV is .34 to .54 in circumcised men as compared to uncircumcised males [3]. Three randomized controlled trial have shown that the relative risk female to male transmission of HIV ranged from .47 to .61 when circumcised males are compared to uncircumcised men [4-6].

A Cochrane review of the effectiveness male circumcision concluded: "Inclusion of male circumcision into current HIV prevention measures guidelines is warranted, with further research required to assess the feasibility, desirability,, and cost effectiveness if implementing the procedure within local contexts" [7].

This evidence led the American Academy of Pediatrics to state that "the preventive health benefits [authors' note: this includes HIV prevention] of NMC outweigh the risks of the procedure and clinicians should routinely provide an unbiased information to the parents so that they can decide whether their child should be circumcised or not." The American College of Obstetricians and Gynecologists also endorsed this statement [8]. The World Health organization and the Joint United Nations Program on HIV/AIDS

*Corresponding author: Richard M. Grimes, Division of General Internal Medicine, University of Texas Health Science Center at Houston, Texas, USA 6431 Fannin, MSB 1.150, Houston, Texas 77030, USA, Tel: 01-713-661-2007; Fax 01- 713-500-6722. E-mail: Richard.M.Grimes@uth.tmc.edu

Received May 18, 2015; Accepted June 13, 2015; Published June 21, 2015

Citation: Pruenglampoo B, Srithanaviboonchai K, Grimes RM, Grimes DE Suwanteerangkul J et al. (2015) Perception, Concern and Acceptability of Neonata Male Circumcision among Postpartum Mothers in Thailand. J AIDS Clin Res 6: 487. doi:10.4172/2155-6113.1000487

Copyright: (c) 2015 Pruenglampoo B, et al. This is an open-access article distributed under the terms of the Creative Commons Attribution License, which permits unrestricted use, distribution, and reproduction in any medium, provided the original author and source are credited. 
also recommend that countries include circumcision as part of a comprehensive HIV prevention strategy [9].

Circumcision of adults, however, can result in significant complications including infections, pain, bleeding, and difficulty in urinating and erectile dysfunction $[10,11]$. When performed in infants, it has the long term effect of decreasing the risk of ulcerative sexually transmitted diseases [12.13], penile cancer [14,15], and urinary tract infections [16,17]. Neonatal Male Circumcision (NMC) is easier, cheaper and has far fewer complications compared to circumcision in adolescents and adults $[18,19]$.

There is great potential for implementing NMC in Thailand. The country has a strong public health and health care infrastructure that has demonstrated the capability to provide very effective HIV prevention. For example, Thailand's national Prevention of Maternal to Child Transmission program, established in 2000, is considered to be the most successful in a resource limited setting [20]. In addition, it has been estimated that $98.7 \%$ of women receive antenatal care and $98.9 \%$ have skilled birth attendance, which is primarily provided by a universal health care system [21]. Thailand also has the highest prevalence (1.3\%) of HIV infection of any country in Asia [22]. While Thailand once was very effective in reducing the incidence of HIV and other sexually transmitted diseases [23], there have been recent studies showing increases in these diseases in IV drug users and young persons $[24,25]$. So, Thailand is suitable for considering promotion of NMC as an additional HIV prevention strategy with the additional benefit of reduced sexually transmitted infections.

There are significant barriers to NMC in Thailand. A recent survey of 562 Thai hospitals in which babies are delivered showed that NMC was seldom performed and that few providers had been trained to perform the procedure. In addition, a majority of physician and nurse respondents from these hospitals held the opinion that NMC was not safe or easy to perform [26]. Two-thirds of these health professionals did not agree that NMC should be performed in their hospitals [26]. It is not known how NMC is perceived by mothers of neonates and whether it is acceptable to them. While there were a number of studies investigating parental acceptance of NMC as an HIV prevention intervention in Africa [27-29], Canada [30], Australia [31], and China [32], there has been no such study from Thailand. The only study about acceptability of MC conducted in the country was about adult MC, not NMC [33].

It is necessary to have parental consent prior to performing a medical procedure on an infant. The most convenient time for NMC is immediately after birth when both the mother and the infant are still in the hospital. So, until parents, particularly mothers, understand the utility of NMC and give permission for its conduct, it is not likely that there will be widespread adoption of it in Thailand. Thus, this study was designed to investigate the perceptions of, concerns about and acceptability of NMC among mothers in Thailand who recently delivered babies.

\section{Materials and Methods}

\section{Study design}

Given the large number of hospitals in Thailand it was impossible construct a random sample of new mothers and so there was no power calculation. Instead, there was an attempt to create a representative sample that might give insight into maternal knowledge and attitudes about NMC. A cross-sectional study was conducted in four provinces. Pathumthani, Khon Kaen, Chiang Mai, and Songkhla, that have a medical school affiliated hospital. These provinces were selected to represent central, northeastern, northern and southern regions in Thailand. In each province, two district hospitals, one provincial hospital, and one medical school hospital were selected as the study sites. For district hospitals, the first one was randomly selected from the ones that were located in the districts adjacent to Amphoe Mueang (the city in the province that contains the administration office of the province) and the second one was randomly selected from the hospitals located a distance from that city. These can be considered to be suburban and rural areas. There is only one provincial and one medical school hospital in each province.

\section{Sampling procedures}

The sample of women at each hospital was determined so as to be proportionate to the number of obstetrical deliveries that occurred at that type of hospital within each selected province during 2010.

Postpartum mothers were eligible to participate in the study if they were 18 years old or older and had given birth within the previous 60 days. Postpartum mothers were approached consecutively at either the postpartum ward or at the postpartum clinic where the mother came for the 6-week postpartum checkup. Two nurses who were permanent staff at each study hospital were selected and trained to administer the questionnaire. They approached women in the obstetric ward or in the post-natal clinic to see if they would be interested in taking part in the study. When a mother agreed, she provided verbal informed consent prior to the receiving the questionnaire.

\section{Questionnaire development and data collecting}

There were two parts to the questionnaire. The first section of the questionnaire included questions on socio-demographics, previous sources of information about circumcision, perceived risk and benefit of NMC, and factors that might be associated with the acceptance of NMC. After completing the first section, the participants were then provided with medically correct and neutral information regarding NMC by the study nurses. This included the definition, an illustration (Figure 1), and NMC's potential benefits and risks. The mothers who were literate read the information contained on a standard information sheet. Mothers who could not read received the same information by having the information sheet read by the nurse. Finally, the mothers were asked if they were willing to have their child circumcised given that the service would be performed by trained physician, at the same hospital where they delivered, and the procedure would be free of charge.

The data was double entered into computer software and was analyzed using descriptive statistics, univariate analysis, and binary logistic regression.

\section{Ethical considerations}

Three institutional review boards (IRB) approved the study. These included the IRBs of; Research Institute for Health Sciences, Chiang Mai University; Faculty of Medicine, Chiang Mai University; and Faculty of Medicine, Prince of Khon Khaen University. Verbal informed consent was allowed by all three IRBs since data collected was not sensitive and no biological sample was collected.

\section{Results}

\section{Basic characteristics of the participants}

The sample consisted of 593 postpartum mothers from the 16 hospitals. The participants were distributed quite equally with regards 


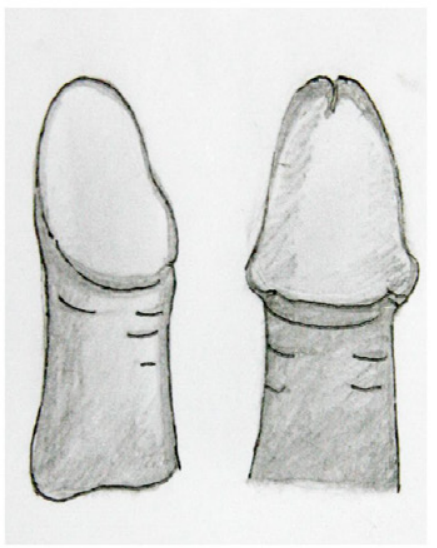

Circumcised penis

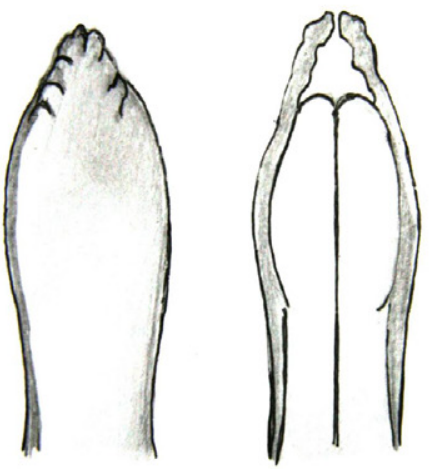

Uncircumcised penis

Figure 1:

to the region they lived. The highest proportion of mothers was from Songkhla in the south (30.7\%) while each of other regions accounted for at least $20 \%$ of total subjects. The majority of postpartum mothers in the study delivered in a medical school hospital (62.7\%), followed by a provincial hospital (26.1\%), and a district hospital (11.2\%) respectively (Table 1 ).

The average age of the participants was 27.6 years. Most $(93.6 \%)$ were married and lived with their spouse at the time of interview. The most frequent education level $(23.8 \%)$ was early secondary, followed by bachelor degree or higher (22.4\%). Eighty six percent of the participants stated that they were Buddhists. With regards to occupation, the most frequent were employees (40.2\%), housewife (33.2\%) and business owner (13.0\%). Eighty five percent of the participants stated that their family income was at least enough for their living (Table 2).

\section{Perception and source of information about male circumcision among postpartum mothers}

Seventy percent of the participants reported that they knew or have heard about MC. Among the postpartum mothers who knew about MC, the top three sources of information were friends or neighbors $(34.7 \%)$, religious sources $(33.5 \%)$ and printed media (23.9\%). Only 16.2 percent of postpartum mothers stated that their husband had been circumcised. The percentages of the participants who had at least one male relative circumcised were 19.2\% (Table 3).
Among 418 postpartum mothers who knew about MC, The most common perceived benefits of NMC recognized by the participants were easier to clean the penis (78.7\%), reduce the risk of penile cancer $(64.8 \%)$, and reduce the risk of sexually transmitted infections (63.6\%) respectively. Half of the participant (50.2\%) thought that it might reduce the risk of cervical cancer of partner while $41.7 \%$ cited reduction in the risk of HIV infection as potential benefit of MC. Pain (85.1\%) and infection (73.0\%) were the most frequent perceived risks of NMC. The two major concerns of the mother towards NMC were safety $(39.1 \%)$ and pain $(26.8 \%)$ (Table $4)$.

\begin{tabular}{|l|c|l|}
\hline \multicolumn{1}{|c|}{$\mathbf{n}$} & $\%$ \\
\hline Province (region) & & \\
\hline Pathumthani (central) & 141 & 23.8 \\
\hline $\begin{array}{l}\text { Khon Khaen } \\
\text { (northeastern) }\end{array}$ & 127 & 21.4 \\
\hline Chiang Mai (northern) & 143 & 24.1 \\
\hline Songkhla (southern) & 182 & 30.7 \\
\hline Type of hospital & & \\
\hline Medical School Hospital & 372 & 62.7 \\
\hline Provincial Hospital & 155 & 26.1 \\
\hline Community Hospital & 66 & 11.2 \\
\hline
\end{tabular}

Table 1: Number and percentage of postpartum mothers by province and type of hospital.

\begin{tabular}{|c|c|c|}
\hline Characteristic & $\mathbf{n}$ & $\%$ \\
\hline \multicolumn{3}{|l|}{$\begin{array}{c}\text { Age (yrs) (Mean }=27.6 \\
S D=5.9)\end{array}$} \\
\hline \multicolumn{3}{|l|}{ Marital status } \\
\hline Married/cohabitating & 554 & 93.6 \\
\hline Divorce/widow/separate & 38 & 6.4 \\
\hline \multicolumn{3}{|l|}{ Education } \\
\hline No education & 20 & 3.4 \\
\hline Elementary (6 yrs) & 70 & 11.8 \\
\hline Early secondary (9 yrs) & 141 & 23.8 \\
\hline Late secondary (12 yrs) & 121 & 20.4 \\
\hline $\begin{array}{l}\text { Vocational school (12-14 } \\
\text { yrs) }\end{array}$ & 101 & 17 \\
\hline $\begin{array}{l}\text { Bachelor degree or higher } \\
\text { ( } \geq 16 \mathrm{yrs})\end{array}$ & 133 & 22.4 \\
\hline Studying & 7 & 1.2 \\
\hline \multicolumn{3}{|l|}{ Religion } \\
\hline Buddhist & 512 & 86.3 \\
\hline Muslim & 62 & 10.5 \\
\hline Christian & 18 & 3 \\
\hline No religion & 1 & 0.2 \\
\hline \multicolumn{3}{|l|}{ Occupation } \\
\hline Employee & 237 & 40.2 \\
\hline Housewife & 197 & 33.4 \\
\hline Business owner & 77 & 13 \\
\hline Other & 79 & 13.4 \\
\hline \multicolumn{3}{|l|}{$\begin{array}{l}\text { Income compared to } \\
\text { expenses of the family }\end{array}$} \\
\hline Income >expense & 220 & 37.5 \\
\hline Income $=$ expense & 278 & 47.4 \\
\hline Income <expense & 88 & 15 \\
\hline
\end{tabular}

Table 2: Demographic characteristics of postpartum mothers. 
Citation: Pruenglampoo B, Srithanaviboonchai K, Grimes RM, Grimes DE, Suwanteerangkul J et al. (2015) Perception, Concern and Acceptability of Neonatal Male Circumcision among Postpartum Mothers in Thailand. J AIDS Clin Res 6: 487. doi:10.4172/2155-6113.1000487

Page 4 of 6

\section{Factors related to acceptability of NMC among postpartum mothers}

Fifty two percent of the respondents said that their communities accepted circumcised men. In their families, mothers (44.0\%) seemed to be the most influential person when come to the decision whether to perform NMC to their babies and followed by fathers $(37.9 \%)$. The mothers stated that the most appropriate times to do NMC were immediately after birth while the mother and the child are still in the hospital (40.0\%), followed by let the boy to decide by himself when he grows up (39.3\%) (Table 5).

\section{Acceptability of NMC among postpartum mothers}

After the postpartum mothers received the information about

\begin{tabular}{|l|c|c|}
\hline Items & $\mathbf{n}$ & $\%$ \\
\hline Know or have heard about male circumcision & & 70.5 \\
\hline Yes & 175 & 29.5 \\
\hline No & & \\
\hline Sources of information on male circumcision* & 145 & 34.7 \\
\hline Friends/neighbors & 140 & 33.5 \\
\hline Religious sources & 100 & 23.9 \\
\hline Printed media & 66 & 15.8 \\
\hline Radio/television & 57 & 13.6 \\
\hline Health Professionals & 37 & 8.9 \\
\hline Internet & 42 & 10 \\
\hline Others & & \\
\hline Husband circumcised & 67 & 16.2 \\
\hline Yes & 317 & 76.6 \\
\hline No & 30 & 7.2 \\
\hline Don't know & & \\
\hline At least one male relative circumcised & 80 & 19.2 \\
\hline Yes & 283 & 68 \\
\hline No & 53 & 12.7 \\
\hline Don't know & & \\
\hline *mothan & & \\
\hline
\end{tabular}

*more than one category could be selected

Table 3: Perception and source of information about male circumcision among postpartum mothers

\begin{tabular}{|l|c|c|}
\hline Items & $\mathbf{n}$ & $\%$ \\
\hline Benefits & & 78.7 \\
\hline Easy to clean penis & 258 & 64.8 \\
\hline Reduce risk of penile cancer & 255 & 63.6 \\
\hline $\begin{array}{l}\text { Reduce risk of sexually transmitted } \\
\text { infection }\end{array}$ & 203 & 50.2 \\
\hline $\begin{array}{l}\text { Reduce risk of cervical cancer in } \\
\text { female partner }\end{array}$ & 169 & 41.7 \\
\hline Reduce the risk of HIV infection & 348 & 85.1 \\
\hline Risks & 298 & 73 \\
\hline Might be painful & 84 & 21.6 \\
\hline Infection of the penis & 96 & 23.6 \\
\hline $\begin{array}{l}\text { Decrease sexual pleasure when } \\
\text { grows up }\end{array}$ & & 39.2 \\
\hline Feeling inferior when grows up & 163 & 38 \\
\hline Top 3 concerns towards NMC & 36 & \\
\hline Safety & 158 & \\
\hline Pain & & \\
\hline Skill of the surgeon & & \\
\hline
\end{tabular}

Table 4: Perceived benefits, risks and concerns of NMC among postpartum mothers who knew about MC.
NMC, $197(33.8 \%)$ of them would choose to have their infants circumcised, 201 (34.5\%) chose the contrary, and 185 (31.7\%) were undecided. In univariate analysis, acceptability of NMC was associated with having religion other than Buddhist compared to Buddhist (OR 2.97; 95\% confidence interval [CI] 1.83-4.83), having education at least 9 years compared to less than 9 years (OR 1.89; 95\%CI 1.31-2.72), had household income more than expense compared to less or equal to expense (OR 1.45; 95\%CI 1.02-2.06), had a circumcised husband compared to uncircumcised or unknown (OR 4.20; 95\%CI 2.37-7.43), and knew of at least a son of other people having been circumcised compared to did not know any such person (OR 2.69; 95\%CI 1.75-4.14).

After adjusting for other variables in a multiple regression, having 9 years or greater of formal education (OR 1.64; 95\% CI 1.01-2.66), had circumcised husband (OR 2.88; 95\% CI 1.11-7.50), and knew of at least child who had been circumcised (OR 1.97; 95\% CI 1.22-3.18) were independent predictors of acceptability to NMC among postpartum mothers (Table 6).

\section{Discussion and Conclusions}

These data point out the difficulty of introducing a potentially beneficial public health practice when there is not a cultural norm to support it. There is a relatively high ignorance about circumcision in that $30 \%$ of mothers have never heard of circumcision. Only onesixth of the women said that their husbands were circumcised and less than a fifth said that they had a male relative who was circumcised. This figure was comparable to Hong-Van tieu et al. [33] who found that only $12.3 \%$ of heterosexual men engaging in high-risk behaviors were circumcised. Two-thirds of the respondents would not allow their sons to be circumcised or were not sure if they would allow it even after receiving a short education on the benefits. And, this was not because they did not comprehend the material in the education program. Most of the respondents could name multiple benefits of NMC including the reduction of disease risks. This suggests that this is not merely a knowledge problem but also an attitude issue.

There is good news for those who would advocate NMC in Thailand. Seventy percent of the mothers of newborns were familiar with circumcision. It is also positive that a third of these mothers could be educated to agree with having their sons circumcised after receiving a one page educational document. This level of approval occurred even though this was asked of them before they had any time to reflect on the matter or consult with their spouses. This suggests that Thai mothers can be educated to accept NMC. It is reasonable to assume that this percent could be increased by continuous reinforcement of the benefits during prenatal visits. It would also seem likely that this percent could be substantially increased if their clinical caregivers were advocates of the procedure. However, the level of support for NMC by health professionals in the previously described study was similar was not high. [26]

So, it is also important to raise public awareness of the benefits of NMC so that it becomes more acceptable in the Thai culture. The primary sources of information of the respondents were friends and neighbors or religious figures. It is likely that these sources do not have accurate medical/scientific information about NMC. Only a small proportion of respondents reported knowing about MC from radio, television, and internet. These are important sources of information for young people in their child bearing years. Understanding of the benefits of NMC could be much improved among young Thais if these media were used to provide NMC information. It is also important to note that mothers who had higher education were more likely to accept NMC. 
Citation: Pruenglampoo B, Srithanaviboonchai K, Grimes RM, Grimes DE, Suwanteerangkul J et al. (2015) Perception, Concern and Acceptability of Neonatal Male Circumcision among Postpartum Mothers in Thailand. J AIDS Clin Res 6: 487. doi:10.4172/2155-6113.1000487

This may result from greater access to health information and a better understanding of the information presented in this study. This finding highlights the importance of simplifying educational materials and using mass media to reach less educated groups.

The most common perceived benefit of NMC, as recognized by the participants, was related to hygiene. This finding is similar to findings of others [27,30]. HIV risk reduction, which could be the main reason for promoting this procedure in Thailand, was only seen as a benefit of NMC by less than half of the participants. This calls for much more emphasis on this benefit in future education programs. Pain and

\begin{tabular}{|l|c|c|}
\hline Items & $\mathbf{n}$ & $\%$ \\
\hline $\begin{array}{l}\text { Do their communities accept men who have } \\
\text { been circumcised? }\end{array}$ & & \\
\hline Yes & 215 & 51.6 \\
\hline No & 144 & 34.5 \\
\hline Not sure & & \\
\hline $\begin{array}{l}\text { Who is the most influential person in the } \\
\text { family to make decision for their babies to get } \\
\text { circumcised? }\end{array}$ & & \\
\hline Mother & 182 & 44 \\
\hline Father & 157 & 37.9 \\
\hline Grandparent/Relatives & 75 & 18.1 \\
\hline $\begin{array}{l}\text { When is appropriate time for their neonatal } \\
\text { circumcision? }\end{array}$ & 164 & 40 \\
\hline $\begin{array}{l}\text { Immediately after birth while the mother and child } \\
\text { are still in the hospital }\end{array}$ & 161 & 39.3 \\
\hline Per baby decision when he grows up & 53 & 12.9 \\
\hline Per religion requirement & 25 & 6.1 \\
\hline When their son comes for vaccination visit & 6 & 1.5 \\
\hline Age > 1 yr & 2 & 0.5 \\
\hline Others & & \\
\hline
\end{tabular}

Table 5: Factors that related acceptability and decision of NMC among postpartum mothers who knew about MC.

\begin{tabular}{|c|c|c|c|}
\hline Characteristics & $\begin{array}{l}\text { Acceptable to } \\
\text { NMC (\%) }\end{array}$ & $\begin{array}{c}\text { Crude OR } \\
(95 \% \mathrm{Cl})\end{array}$ & $\begin{array}{c}\text { Adjusted OR } \\
(95 \% \mathrm{Cl})\end{array}$ \\
\hline \multicolumn{3}{|l|}{ Age (years) } & \multirow{3}{*}{$\mathrm{a}$} \\
\hline$<30$ & 32.8 & 1 & \\
\hline$\geq 30$ & 35.5 & $1.13(0.79-1.61)$ & \\
\hline \multicolumn{4}{|l|}{ Religion } \\
\hline Buddhist & 30.4 & 1 & 1 \\
\hline Others & 56.4 & $2.97(1.83-4.83)$ & $\begin{array}{l}1.07(0.43- \\
2.70)\end{array}$ \\
\hline \multicolumn{4}{|l|}{ Education } \\
\hline Less than 9 years & 25.4 & 1 & 1 \\
\hline 9 years or more & 39.2 & $1.89(1.31-2.72)$ & $\begin{array}{l}1.64(1.01- \\
2.66)\end{array}$ \\
\hline \multicolumn{4}{|l|}{ Household income } \\
\hline Less or equal to expense & 30.8 & 1 & 1 \\
\hline More than expense & 39.2 & $1.45(1.02-2.06)$ & $\begin{array}{l}1.50(0.96- \\
2.33)\end{array}$ \\
\hline \multicolumn{4}{|l|}{ Husband circumcised } \\
\hline No or don't know & 30.6 & 1 & 1 \\
\hline Yes & 66.7 & $4.20(2.37-7.43)$ & $\begin{array}{c}2.88(1.11- \\
7.50)\end{array}$ \\
\hline \multicolumn{4}{|l|}{$\begin{array}{l}\text { Son of known person } \\
\text { circumcised }\end{array}$} \\
\hline No or don't know & 30.2 & 1 & 1 \\
\hline Yes & 53.8 & $2.69(1.75-4.14)$ & $\begin{array}{c}1.97(1.22- \\
3.18)\end{array}$ \\
\hline
\end{tabular}

a not included in multivariate analysis

Table 6: Analysis of acceptability of NMC among the postpartum mothers. infection of the penis were the most frequent perceived risk of NMC These findings were similar to a number of other studies $[31,32,34]$ and could be reduced by better education of mothers and training of clinicians.

Both mothers and fathers seemed to be of comparable influence when deciding whether to circumcise the newborn. This finding was in contrast with the results of studies from China [32] and Zimbabwe [28] that found that fathers had the ultimate decision over this issue. So, in the Thai context, health providers will have to make certain to approach both parents when providing information and offering this service. This communication should start early during the antenatal care so that the couples could inform hospital staff about their decision before the time of delivery.

Nearly the same percentages of the mothers stated that the appropriate times for MC were within 3 days after delivery (40\%) and when the boys decide by themselves when grows up (39\%). This high proportion of responses preferring delayed circumcision might reflect not enough information being provided about the complications of circumcision in older males and the safety in neonates. [25]. Future education programs will have to be directed toward parents about the reasons why it best to have it done as a neonate.

In summary, there does not seem to be any deep seated opposition to NMC nor is there a groundswell of approval either. One might consider NMC to be culturally neutral with some evidence that even modest educational efforts can impact mothers' decisions in favor of NMC. However, the previous study [26] suggests that both parents and health professionals will need to be educated about the benefits of NMC. If the Thai health professional culture is opposed, it is unlikely that this highly beneficial procedure will ever be implemented.

\section{Acknowledgments}

This study was supported by the National Research University Project under Thailand's Office of the Higher Education Commission and Baylor-UT Houston Center for AIDS Research (CFAR), a program funded by the US National Institutes of Health (NIH) (Al036211). We thank the staffs of 16 hospitals who facilitated the study. Finally, we are grateful to all participants who participated in this study.

\section{References}

1. Srithanaviboonchai K, GrimesRM, Suwanteerankul J, Thaikla K, Korana J, et al. (2014) Capability of Thailand to implement newborn male circumcision: a nation-wide survey. AIDS Care 26: 20-25.

2. Srithanaviboonchai K, Grimes RM (2012) Why Thailand should consider promoting neonatal circumcision? Southeast Asian J Trop Med Public Health 43: 1218-1226.

3. Weiss HA, Quigley MA, Hayes RJ (2000) Male circumcision and risk of HIV infection in sub-Saharan Africa: a systematic review and meta-analysis. AIDS 14: 2361-2370.

4. Auvert B, Taljaard D, Lagarde E, Sobngwi-Tambekou J, Sitta R, et al. (2005) Randomized, controlled intervention trial of zmale circumcision for reduction of HIV infection risk: the ANRS 1265 Trial. PLoS Med 2: e298.

5. Bailey RC, Moses S, Parker CB, Agot K, Maclean I, et al. (2007) Male circumcision for HIV prevention in young men in Kisumu, Kenya: a randomised controlled trial. Lancet 369: 643-656.

6. Gray RH, Kigozi G, Serwadda D, Makumbi F, Watya S, et al. (2007) Male circumcision for HIV prevention in men in Rakai, Uganda: a randomised trial. Lancet 369: 657-666.

7. Siegfried N, Muller M, Deeks JJ, Volmink J. Male circumcision for prevention of heterosexual acquisition of HIV in men. Cochrane Database Syst Rev 2009; (3) :CD003362.

8. American Academy of Pediatrics Task Force on Circumcision (2012) Circumcision policy statement. Pediatrics 130: 585-586.

9. World Health Organization and the Joint United Nations Program on HIV/ AIDS (2007) New Data on Male Circumcision and HIV Prevention: Policy and Programme Implications. Geneva.

10. Bailey RC, Egesah O, Rosenberg S (2008) Male circumcision for HIV 
Citation: Pruenglampoo B, Srithanaviboonchai K, Grimes RM, Grimes DE, Suwanteerangkul J et al. (2015) Perception, Concern and Acceptability of Neonatal Male Circumcision among Postpartum Mothers in Thailand. J AIDS Clin Res 6: 487. doi:10.4172/2155-6113.1000487

Page 6 of 6

prevention: a prospective study of complications in clinical and traditional settings in Bungoma, Kenya. Bull World Health Organ 86: 669-677.

11. Herman-Roloff A, Bailey RC, Agot K (2012) Factors associated with the safety of voluntary medical male circumcision in Nyanza province, Kenya. Bull World Health Organ 90: 773-781.

12. Schiffer JT, Corey $L$ (2009) New concepts in understanding genital herpes. Curr Infect Dis Rep 11: 457-464.

13. Tobian AA, Serwadda D, Quinn TC, Kigozi G, Gravitt PE, et al. (2009) Male circumcision for the prevention of HSV-2 and HPV infections and syphilis. N Engl J Med 360: 1298-1309.

14. Novara G, Galfano A, De Marco V, Artibani W, Ficarra V (2007) Prognostic factors in squamous cell carcinoma of the penis. Nat Clin Pract Urol 4: 140-146.

15. Tsen HF, Morgenstern H, Mack T, Peters RK (2001) Risk factors for penile cancer: results of a population-based case-control study in Los Angeles County (United States). Cancer Causes Control 12: 267-277.

16. Shaikh N, Morone NE, Bost JE, Farrell MH (2008) Prevalence of urinary tract infection in childhood: a meta-analysis. Pediatr Infect Dis J 27: 302-308.

17. Schoen EJ, Colby CJ, Ray GT (2000) Newborn circumcision decreases incidence and costs of urinary tract infections during the first year of life. Pediatrics 105: 789-793.

18. Weiss HA, Larke N, Halperin D, Schenker I (2010) Complications of circumcision in male neonates, infants and children: a systematic review. BMC Urol 10: 2.

19. WHO, UNAIDS, JHPIEGO (2007) Manual for Male Circumcision under Local Anaesthesia. Version 2.5 b. Geneva.

20. Paintsil E, Andiman WA (2009) Update on successes and challenges regarding mother-to-child transmission of HIV. Curr Opin Pediatr 21: 94-101.

21. Kongsri S, Limwattananon S, Sirilak S, Prakongsai P, Tangcharoensathien $V$ (2011) Equity of access to and utilization of reproductive health services in Thailand: national Reproductive Health Survey data, 2006 and 2009. Reprod Health Matters 19: 86-97.

22. AVERT (2012) HIV and AIDS in Asia.

23. Celentano DD, Nelson KE, Lyles CM, Beyrer C, Eiumtrakul S, et al. (1998) Decreasing incidence of HIV and sexually transmitted diseases in young Thai men: evidence for success of the HIVIAIDS control and prevention program. AIDS 12: F29-36.
24. Sutcliffe CG, Aramrattana A, Sherman SG, Sirirojn B, German D, et al. (2009) Incidence of HIV and sexually transmitted infections and risk factors for acquisition among young methamphetamine users in northern Thailand. Sex Transm Dis 36: 284-289.

25. Latimore AD, Aramrattana A, Sherman SG, Galai N, Srirojn B, et al. (2013) Sexually transmitted infection risk behaviors in rural Thai adolescents and young adults: support for sex- and age-specific interventions. Sex Transm Dis 40: $216-220$.

26. Srithanaviboonchai K, Grimes RM, Suwanteerankul J, Thaikla K, Korana J, et al. (2014) Capability of Thailand to implement newborn male circumcision: a nation-wide survey. AIDS Care 26: 20-25.

27. Waters E, Li M, Mugisa B, Bowa K, Linyama D, et al. (2013) Acceptability and uptake of neonatal male circumcision in Lusaka, Zambia. AIDS Behav 17: 2114-2122.

28. Mavhu W, Hatzold K, Laver SM, Sherman J, Tengende BR, et al. (2012) Acceptability of early infant male circumcision as an HIV prevention intervention in Zimbabwe: a qualitative perspective. PLoS One 7: e32475.

29. Plank RM, Makhema J, Kebaabetswe P, Hussein F, Lesetedi C, et al. (2010) Acceptability of infant male circumcision as part of HIV prevention and male reproductive health efforts in Gaborone, Botswana, and surrounding areas. AIDS Behav 14: 1198-1202.

30. Rediger C, Muller AJ (2013) Parents' rationale for male circumcision. Can Fam Physician 59: e110-115.

31. Xu B, Goldman H (2008) Newborn circumcision in Victoria, Australia: reasons and parental attitudes. ANZ J Surg 78: 1019-1022.

32. Pan L, Zhang A, Shen R, Wang Z (2012) Acceptability of early infant male circumcision among Chinese parents: strategy implications of HIV prevention for China. BMC Public Health 12: 738.

33. Tieu HV, Phanuphak N, Ananworanich J, Vatanparast R, Jadwattanakul T, et al. (2010) Acceptability of male circumcision for the prevention of HIV among high-risk heterosexual men in Thailand. Sex Transm Dis 37: 352 355.

34. Young MR, Bailey RC, Odoyo-June E, Irwin TE, Obiero W, et al. (2012) Safety of over twelve hundred infant male circumcisions using the Mogen clamp in Kenya. PLoS One 7: e47395. 